\title{
OPEN Interactions between parasitic helminths and gut microbiota in wild tropical primates from intact and fragmented habitats
}

\author{
Claudia Barelli ${ }^{1,2 \varpi}$, Claudio Donati ${ }^{3}$, Davide Albanese ${ }^{3}$, Barbora Pafčo ${ }^{4,5}$, David Modrý $y^{4,6,7}$, \\ Francesco Rovero ${ }^{2} \&$ Heidi C. Hauffe ${ }^{1}$
}

The mammalian gastrointestinal tract harbours a highly complex ecosystem composed of a variety of micro- (bacteria, fungi, viruses, protozoans) and macro-organisms (helminths). Although most microbiota research focuses on the variation of single gut components, the crosstalk between components is still poorly characterized, especially in hosts living under natural conditions. We investigated the gut micro-biodiversity (bacteria, fungi and helminths) of 158 individuals of two wild non-human primates, the Udzungwa red colobus (Procolobus gordonorum) and the yellow baboon (Papio cynocephalus). These species have contrasting diets and lifestyles, but live sympatrically in both human-impacted and pristine forests in the Udzungwa Mountains of Tanzania. Using non-invasive faecal pellets, helminths were identified using standard microscopy while bacteria and fungi were characterized by sequencing the $\mathrm{V} 1-\mathrm{V} 3$ variable region of the $16 \mathrm{~S}$ rRNA gene for bacteria and the ITS1-ITS2 fragment for fungi. Our results show that both diversity and composition of bacteria and fungi are associated with variation in helminth presence. Although interactions differed by habitat type, in both primates we found that Strongyloides was negatively associated and Trichuris was positively associated with bacterial and fungal richness. To our knowledge, this is one of the few studies demonstrating an interaction between helminth and gut microbiota communities in wild nonhuman primates.

Healthy mammalian gastrointestinal tracts harbour a complex ecosystem where micro- (i.e. bacteria and fungi) and macrobiota (i.e. protists and helminths) co-exist and have co-evolved in association with their mutual hosts $^{1,2}$. As the bacterial community exceeds all other components within the gut in terms of number and species diversity ${ }^{3}$, our knowledge of the microbiota is shaped by a disproportionate focus on this gut component. A plethora of evidence suggests that a rich and diverse gut bacterial community is beneficial to host health ${ }^{4-6}$ by maintaining important metabolic and immune functions ${ }^{7-9}$, and contributing to colonization resistance against enteric pathogens ${ }^{10-12}$. However, other relevant (but mostly neglected) gut components are also potentially beneficial or neutral depending on species and context. For example, although they have been mainly studied for their pathogenic characteristics ${ }^{13}$, gut helminths secrete an array of molecules that can directly affect host immune response ${ }^{14}$, or may do so indirectly by interacting with the gut microbiota by modifying bacterial richness and diversity ${ }^{15-19}$.

Although the field is developing quickly, little information is available on the details of micro-/macrobiota interactions in the gut, and interactions of this microdiversity with the host ${ }^{20}$. The majority of studies focussing on this topic derive from laboratory animal experiments ${ }^{21-23}$, but few observations in humans ${ }^{24,25}$ and wild nonhuman animals ${ }^{19,26}$ have revealed associations between gut bacterial communities and helminth infection (but $\operatorname{se}^{27,28}$. Due to the potential beneficial consequences of such interactions for the overall health and well-being

\footnotetext{
${ }^{1}$ Conservation Genetic Research Unit, Research and Innovation Centre, Fondazione Edmund Mach, S. Michele All'Adige, Italy. ${ }^{2}$ Department of Biology, University of Florence, Sesto Fiorentino, Italy. ${ }^{3}$ Computational Biology Research Unit, Research and Innovation Centre, Fondazione Edmund Mach, S. Michele All'Adige, Italy. ${ }^{4}$ Department of Pathology and Parasitology, University of Veterinary Sciences, Brno, Czech Republic. ${ }^{5}$ Institute of Vertebrate Biology, Czech Academy of Sciences, Brno, Czech Republic. ${ }^{6}$ Biology Centre, Institute of Parasitology, Czech Academy of Sciences, Ceske Budejovice, Czech Republic. ${ }^{7}$ Department of Botany and Zoology, Faculty of Science, Masaryk University, Brno, Czech Republic. ${ }^{\boxplus}$ email: barelli.cla@gmail.com
} 
of the hosts (e.g. dampening allergic responses and ameliorating of gut dysfunction in humans ${ }^{29}$ ), investigating the gut communities of animal species closely related to humans (i.e. non-human primates) living under natural conditions is of particular relevance. Studies of these associations will provide a critical foundation to understanding the potential mechanisms that underpin the interplay between helminths, microbiota and hosts, and will deepen our awareness of animal health with possible conservation implications.

Non-human primates represent a crucial element of tropical ecosystems, contributing to forest regeneration and ecosystem health ${ }^{30}$. However, they are facing escalating loss and fragmentation of optimal habitat, making this mammalian group one of the most threatened on Earth ${ }^{31}$. Recent research we conducted on primates living sympatrically in human-modified and pristine habitats has highlighted the impact of habitat changes on gut bacterial and fungal diversity ${ }^{32,33}$, as well as on helminth infections ${ }^{34,35}$. Although a few recent studies have evaluated the diversity and composition of the gut bacterial communities of non-human primates naturally infected by helminths $s^{36-39}$, here we compare both the bacterial and fungal components in helminth-positive and helminth-negative individuals to investigate: (i) whether bacterial and fungal richness and/or composition vary in primates with different ecological adaptations residing in either pristine or human-impacted forests; (ii) which bacterial and fungal taxa are responsible for such variation; and (iii) which of the detected helminths interplay with bacterial and fungal richness.

\section{Results}

This paper investigated the interactions between helminth presence and gut microbiota components (bacteria and fungi) in two primate species (red colobus monkeys and yellow baboons) living in two forest types (intact and fragmented). As reported in ${ }^{35}$, of 158 faecal samples collected from 89 red colobus and 69 yellow baboons $76.6 \%$ (63.3\% for red colobus and $95.6 \%$ for yellow baboons, respectively) were positive for eggs of at least one of the five helminth types identified, two of which (nematodes) could be classified to genus (Strongyloides, Trichuris), while another three to higher taxonomic levels (dicrocoeliid trematodes, and spirurid and strongylid nematodes). No metazoan larvae or adults were detected with the gauze-washing method. Instead ${ }^{32}$, showed that the most prevalent bacterial phyla in both red colobus and baboons were Firmicutes, Bacteroidetes, Proteobacteria and Spirochetes, accounting for $75.3 \%$ and $84.6 \%$ of the total bacterial amplicons, respectively; the four prevalent and classified phyla of fungi were Ascomycota, Basidiomycota and Zygomycota for both host species.

Our analysis here showed that helminth presence was associated with gut microbiota richness and composition for three of the five helminth taxa found in the two primate species studied here: Strongyloides, strongylid nematodes, and Trichuris. The same three taxa were also the most prevalent helminth types, both in yellow baboons (85.5\%, 75.4\% and 23.4\%, respectively) and Udzungwa red colobus (43.9\%, $11.2 \%$ and $38.8 \%$, respectively; see details in ${ }^{35}$ ). Specifically, yellow baboons helminth-positive for strongylid nematodes had lower bacterial richness than helminth-negative individuals living in the Magombera fragmented forest (hereafter FF: fragmented forest $)\left(P=2.03 \times 10^{-7}\right.$, helminth-positive: $\mathrm{N}=6$, helminth-negative: $\mathrm{N}=33$, Tukey post-hoc test, see "Methods" section; Fig. 1a), but the opposite association was found in the Mwanihana protected forest (PF) (i.e. individuals helminth-positive for strongylid nematodes had higher bacterial richness; $\mathrm{P}=0.01$, helminth-positive: $\mathrm{N}=19$, helminth-negative: $\mathrm{N}=11$ ). Instead, baboons helminth-positive for Strongyloides had lower bacterial richness than helminth-negative individuals in both $\mathrm{FF}\left(\mathrm{P}=5.30 \times 10^{-15}\right.$, helminth-positive: $\mathrm{N}=35$, helminthnegative: $\mathrm{N}=4$; Fig. 1a) and $\mathrm{PF}\left(\mathrm{P}=9 \times 10^{-6}\right.$, helminth-positive: $\mathrm{N}=24$, helminth-negative: $\mathrm{N}=6$; Fig. 1a). In addition, a positive association between Trichuris and bacterial richness was also found in individuals living in $\mathrm{PF}\left(\mathrm{P}=1.26 \times 10^{-12}\right.$, helminth-positive: $\mathrm{N}=12$, helminth-negative: $\mathrm{N}=18$; Fig. 1a).

Similar to the yellow baboon, for red colobus monkeys, we detected associations between bacterial richness and helminth presence for the same three helminth taxa: strongylid nematodes, Strongyloides and Trichuris. Specifically, we found negative associations between the presence of both strongylid nematodes and Strongyloides and bacterial richness in animals from $\mathrm{PF}\left(\mathrm{P}=9.84 \times 10^{-9}\right.$, helminth-positive: $\mathrm{N}=4$, helminth-negative: $\mathrm{N}=40$; and $\mathrm{P}=1.69 \times 10^{-10}$, helminth-positive: $\mathrm{N}=7$, helminth-negative: $\mathrm{N}=37$, respectively; Fig. 1a), while the presence of Trichuris was positively associated with bacterial richness in red colobus living in FF $\left(\mathrm{P}=1.44 \times 10^{-7}\right.$, helminth-positive: $\mathrm{N}=12$, helminth-negative: $\mathrm{N}=32$; Fig. 1a; see Table $\mathrm{S} 1$ for details). Using Shannon entropy as a measure of bacterial diversity, we found no significant differences associated with helminth presence (Table S2).

Analyses of the interactions between gut microbiota composition, measured by Bray-Curtis dissimilarities, and helminth presence/absence were less clear cut (Fig. 1b,c): using PERMANOVA we found that only Strongyloides in red colobus monkeys appeared to be associated with gut bacterial composition between individuals infected and non-infected with these nematodes in $\mathrm{FF}(\mathrm{P}=0.003$; Fig. 1c). DESeq2 results showed that among the bacterial taxa that could explain this difference, 17 were enriched in the animals infected with Strongyloides; 11 of these belonged to the order Clostridiales (mainly Lachnospiraceae and Ruminococcaceae families), two to the Bacteroidales and the remaining four were unclassified (Table S3). Among the genera identified, Pseudoflavonifractor was overrepresented in the red colobus infected by Strongyloides.

As for bacteria, using a GLM (see "Methods") to model the effect of helminth presence on fungal richness, we found a positive association between fungal richness and the presence of three helminth types (strongylid nematodes: $\mathrm{P}=6.92 \times 10^{-7}$, post-hoc Tukey test, helminth-positive: $\mathrm{N}=33$, helminth-negative: $\mathrm{N}=6$; Strongyloides: $\mathrm{P}=4.35 \times 10^{-6}$; Trichuris: $\mathrm{P}=0.006$, helminth-positive: $\mathrm{N}=35$, helminth-negative: $\mathrm{N}=4$; Fig. 2a, upper panel) in yellow baboons living in FF. Moreover, we found a positive association between fungal richness and the presence of strongylid nematodes in baboons from $\mathrm{PF}\left(\mathrm{P}=6.89 \times 10^{-7}\right.$, helminth-positive: $\mathrm{N}=19$, helminth-negative: $\mathrm{N}=11$; Fig. 2a, upper panel). For red colobus monkeys, we found a negative association between fungal richness and strongylid presence in animals living in $\mathrm{PF}\left(\mathrm{P}=1.36 \times 10^{-4}\right.$, helminth-positive: $\mathrm{N}=4$, helminth-negative: $\mathrm{N}=40$; Fig. 2a, lower panel) as well as a positive association between fungal richness and Strongyloides presence in animals from $\mathrm{FF}\left(\mathrm{P}=2.73 \times 10^{-7}\right.$, helminth-positive: $\mathrm{N}=7$, helminth-negative: $\mathrm{N}=37$; Fig. 2a, lower panel $)$. All 
a

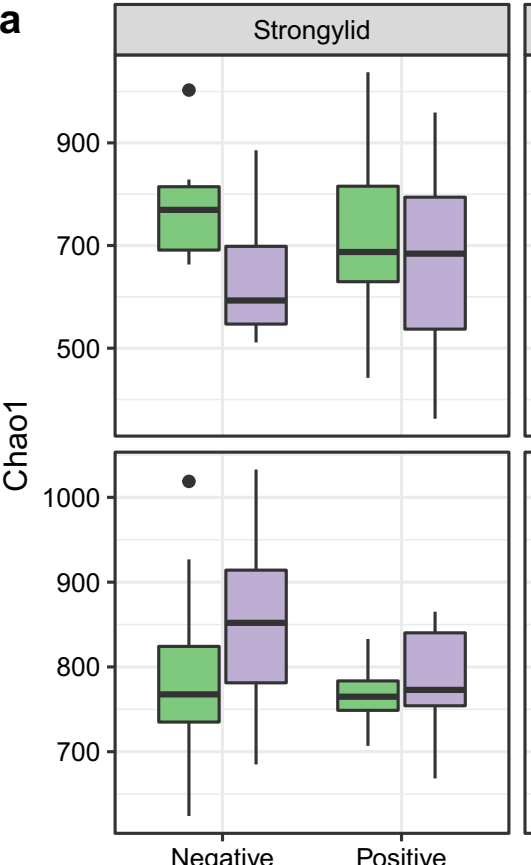

Negative


Negative

Positive Infected

b
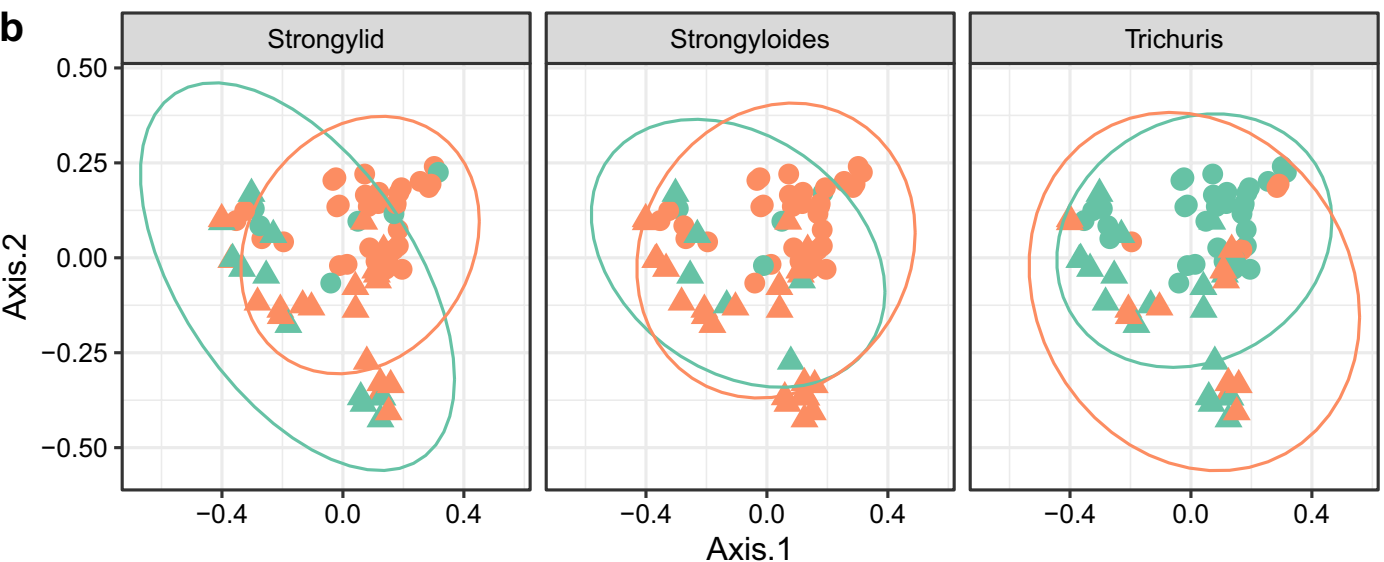

Helminth Presence

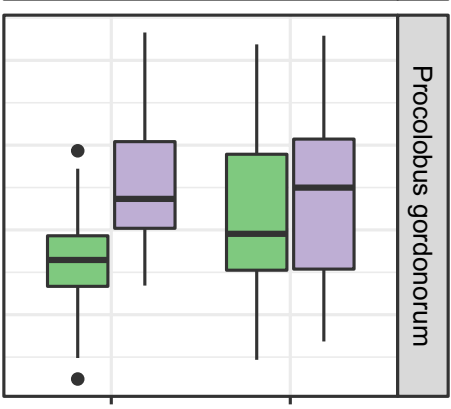

Negative Positive

Forest 可 $F F$ E PF
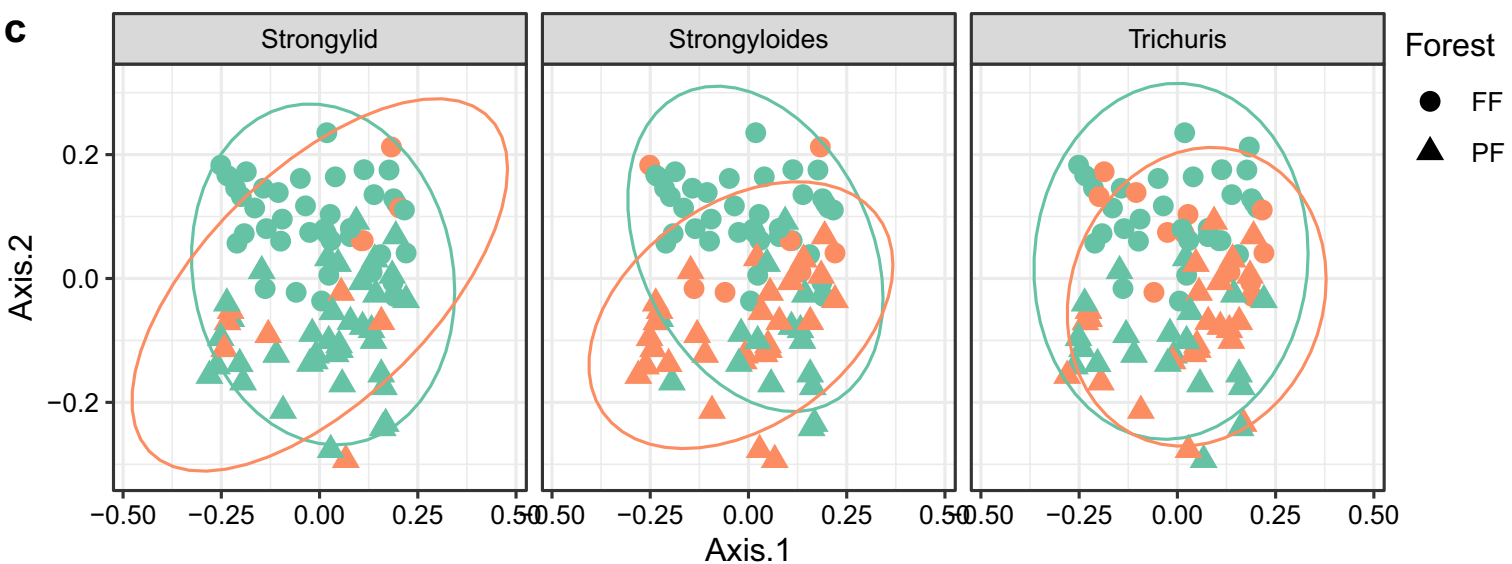

Figure 1. Diversity of gut bacterial communities in yellow baboons and Udzungwa red colobus in two forest types. (a) Comparison of bacterial richness measured by Chaol estimator and $(\mathbf{b}, \mathbf{c})$ bacterial composition measured by Bray-Curtis dissimilarities for helminth negative and positive faecal samples. Panels from left to right focus on three helminth taxa: strongylid nematodes, Strongyloides, and Trichuris present in yellow baboons, Papio cynocephalus [upper panel in (a); (b)], and Udzungwa red colobus monkeys, Procolobus gordonorum [bottom panel in (a); (c)], living in the forest fragment of Magombera [FF: green in (a), circle in (b) and (c)] or the protected forest of Mwanihana [PF: purple in (a); triangle in (b) and (c)] in the Udzungwa Mountains of Tanzania. In (a), the horizontal line in the boxplot indicates the median, the box extends to the 25th-75th percentile and the whiskers extends to the largest value no further than $1.5^{*} \mathrm{IQR}$ from the hinges. In $(\mathbf{b})$ and $(\mathbf{c})$ colours represent helminth negative (green) and positive (orange) samples. 
a
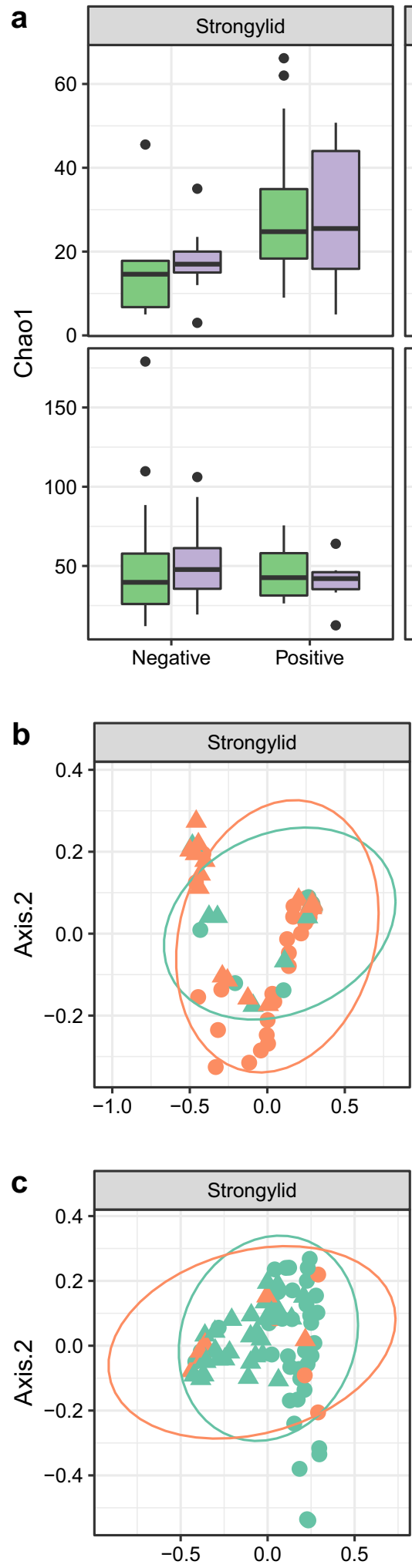
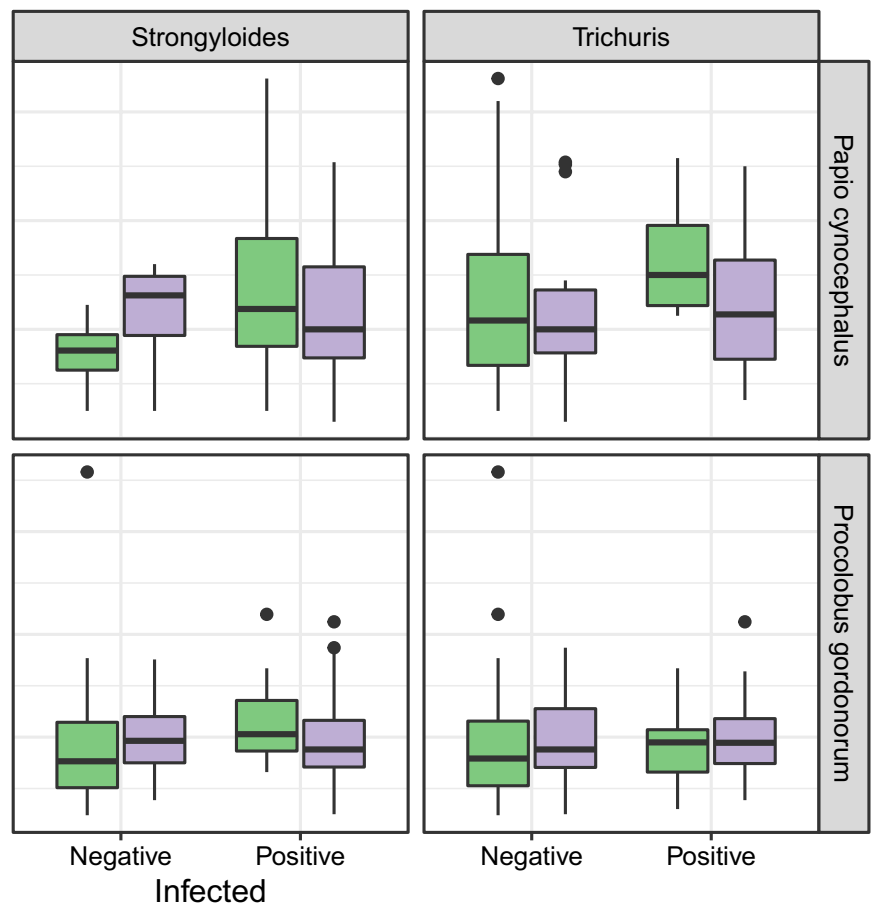

Forest

EF 鸟 PF

Helminth Presence
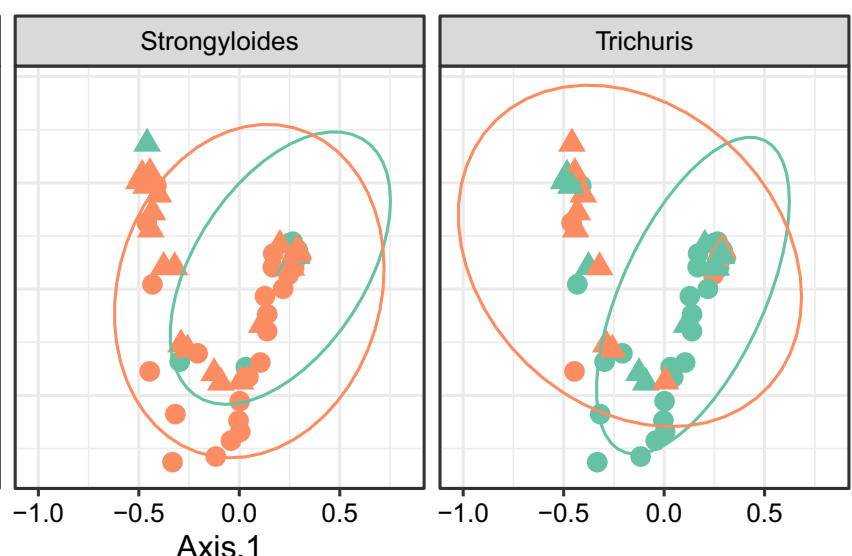

- - Neg
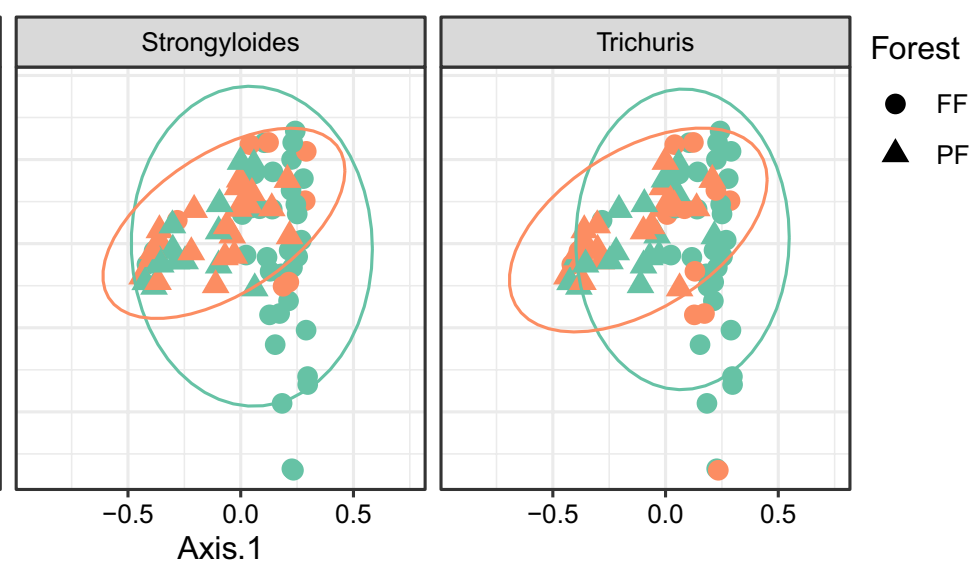

Figure 2. Diversity of gut fungal communities in yellow baboons and Udzungwa red colobus in different forest types. (a) Comparison of fungal richness measured by Chaol estimator and (b,c) fungal composition measured by Bray-Curtis dissimilarities for helminth negative and positive faecal samples. Panels from left to right focus on three helminth taxa: strongylid nematodes, Strongyloides, and Trichuris present in yellow. In (a), the horizontal line in the boxplot indicates the median, the box extends to the 25th-75th percentile and the whiskers extends to the largest value no further than $1.5{ }^{*} \mathrm{IQR}$ from the hinges. In (b) and (c) colours represent helminth negative (green) and positive (orange) samples. 
other comparisons were not statistically significant (Table S5). As for bacteria, we found no significant association between helminth presence and fungal diversity measured by Shannon entropy (Table S5).

Similarly to bacteria, limited associations were observed between the fungal composition and helminth positive and negative individuals. For both red colobus monkeys and yellow baboons individuals positive and negative for Trichuris showed different gut fungal compositions $(\mathrm{P}=0.015$ and 0.03 respectively, Fig. $2 \mathrm{~b}, \mathrm{c})$. However, in both cases a significant inhomogeneity of dispersions around centroids was identified (ANOVA test $\mathrm{P}=0.017$ and 0.010, respectively). DESeq2 identified the family Xylariaceae to be enriched in individuals infected with Trichuris (Table S6).

\section{Discussion}

Here we present the associations between gut bacterial and fungal communities (using 16S rRNA and ITS1-ITS2 amplicon sequencing) and the presence or absence of helminths (measured as shedding of eggs via standard flotation methods and optical microscopy) in two species of wild non-human primates living in the same intact and human-modified tropical forest blocks. We found that changes in gut microbiota richness and diversity in both primate species were associated with the presence of certain helminth types, but that this variation was also affected by habitat. Given the known effects of low gut microbiota diversity in human health and laboratory animals, the loss of natural levels of micro-biodiversity could have wide-ranging and devastating effects on the survival of wild animal species, but the drivers and rate of loss in free-living populations is virtually unknown. Our study provides a novel addition to the rare studies ${ }^{36,37,39}$ investigating the associations between bacterial communities and helminth presence in wild non-human primates, and, for the first time, including fungal communities in the analyses.

To the best of our knowledge this is the first study that uses ITS1-2 Illumina MiSeq technology to characterize gut fungal communities and associate them with helminth presence.

To better understand the biological meaning of the observed associations, we restricted our discussion here to the two soil-transmitted helminths, namely Trichuris sp. and Strongyloides sp. since these taxa are present in most social groups of both primate species ( $94.6 \%$ and $77.2 \%$ of individuals, including all social groups for yellow baboon and red colobus, respectively), and more thoroughly discussed in the literature than the broader taxonomic helminth groups that could be identified here. Helminths of both genera parasitize a wide variety of different mammalian hosts ${ }^{40,41}$, although they have different life cycles. Embryonated eggs of Trichuris spp. are shed in the faeces; larvae develop inside the eggs in a moist environment and are ingested by new hosts with food, water, and soil. Once in the small intestine, Trichuris eggs are stimulated by the cecal microbiota to hatch and first-stage larvae embed themselves into the mucosa of the large intestine; after mating, female whipworms produce eggs to complete the cycle ${ }^{42}$. Instead, Strongyloides leave the host either as first stage larvae or embryonated eggs shed into the environment, but go through several free-living stages before being ingested, and inhabiting the mucosa of the small intestine ${ }^{41,43}$. Previous studies of bacterial microbiota and the soil-transmitted Trichuris and Strongyloides helminths have reported various results, from no association (i.e. Trichuris sp. in rural Ecuadorian children ${ }^{28}$; Strongyloides sp. in wild western chimpanzee ${ }^{44}$ ) to alteration of the gut microbiota, by reducing ${ }^{16,45}$ or increasing ${ }^{24,46,47}$ bacterial richness and diversity. We found robust patterns of associations between bacterial and fungal components of the microbiota and helminths across the two primate species. Bacterial and fungal richness increased, and fungal composition changed when individual primates were infected by Trichuris, while bacterial richness declined in individuals infected with Strongyloides. This was generally true for both the leafeating, arboreal red colobus monkey and the omnivorous, terrestrial yellow baboon, although habitat also had some effect. Presence of strongylid nematodes, Strongyloides or Trichuris all increased fungal richness in yellow baboons in FF, while nematode presence (strongylid nematodes, Strongyloides) was associated with lower bacterial richness in this species in the same habitat. Nematode presence (strongylid nematodes, Strongyloides) was also associated with lower bacterial richness in red colobus, but in PF. Although studies of the interactions between helminths and microbiota in wild animal populations are still relatively new, we speculate that the discrepancy found here may derive from a temporary instability in microbiota composition as a result of helminth infections which may recover over time, as already found in humans under controlled settings ${ }^{17}$. Further longitudinal studies on the same wild populations could help to fulfil this gap and reveal the actual influence of each gut component over time.

However, it has been suggested previously that a high level of bacterial richness and diversity is considered a desirable trait ${ }^{5,48}$. Moreover, Trichuris infection is known to ameliorate inflammatory bowel disorders in humans ${ }^{49}$. As shown in studies conducted on humans ${ }^{24,46}$ and in a pioneer study on non-human primates ${ }^{18}$, Trichuris infections were also beneficial to restoring bacterial diversity. Indeed, after being therapeutically infected with Trichuris gut bacterial communities were reversed in juvenile rhesus macaques (Macaca mulatta) with colitis as bacterial richness was restored to levels comparable to those of healthy macaques ${ }^{18}$. Interestingly, our findings in wild primates agree with these results, showing a positive association between Trichuris presence and bacterial richness. The positive interaction between Trichuris and bacterial richness we found in Udzungwa red colobus inhabiting FF are particularly intriguing, since these same populations have been shown to suffer loss of bacterial diversity due to the poorer diet (i.e. lower tree diversity compared to intact forests) in this degraded habitat ${ }^{32,33}$. Similarly, the same association found in yellow baboons was restricted to individuals living in the pristine forest, that have a lower bacterial richness compared to animals living in the human-modified forest, where they supplement their diet by raiding crops and feeding on human organic waste. Thus, positive associations between Trichuris presence and bacterial richness in our wild primate models may reflect an ecological strategy to ameliorate low gut microbiota.

In contrast to the results for Trichuris, both Udzungwa red colobus (in PF) and yellow baboons (in both $\mathrm{PF}$ and FF) positive for Strongyloides had lower bacterial richness compared to Strongyloides negative ones. 
This apparently contradicts the studies conducted in human and non-human primates which found a positive association ${ }^{46,47}$ or no association ${ }^{44}$ between Strongyloides and bacterial richness. However, an experimental study conducted on mice infected with $S$. venezuelensis revealed a reduction in bacterial richness at peak of infection ${ }^{45}$, reflecting temporary bacterial alteration potentially due to gut immune responses. Therefore, we cannot exclude the possibility that the lower bacterial richness in Strongyloides-individuals observed here also reflect a transitory effect characteristic of this helminth in any habitat.

Strongyloides secrete a variety of proteins in the host gut, which have antimicrobial activities leading to alteration in bacterial diversity and composition as also recently observed in laboratory mice ${ }^{50}$. In fact, while we observed reduction of gut bacterial diversity in association with Strongyloides infection, the concurrent change in beta diversity (reflecting a variation in bacterial composition) shows that primate species respond differently to helminth presence. Changes in bacterial composition for the Udzungwa red colobus in PF appears to have been driven by Lachnospiraceae and Ruminococcaceae bacterial families. Both families are associated with degradation of complex plant material like cellulose and lignin ${ }^{51,52}$, which may well reflect their folivorous diet, as also found in most of the leaf-eating primates and ruminants ${ }^{53,54}$. However, although both families are associated with energy metabolic advantages, their high abundance has been related to metabolic disorders ${ }^{55,56}$. Moreover, the genus Pseudoflavonifractor, a biomarker of obesity and diabetes, was also overrepresented in individuals infected by Strongyloides, implying that, besides being associated with an overall reduction of bacterial richness, Strongyloides may contribute to the emergence of less beneficial bacterial taxa and thus, to the disruption of the metabolic balance within a healthy gut ${ }^{57}$.

No studies in either experimental and natural settings are available on the interaction between gut fungal communities and the helminths taxa we identified here, although some human models have shown that fungal taxa may be positively associated with parasitic colonization by Blastocystis ${ }^{58}$, such as Saccharomyces boulardii ${ }^{59}$, as well as Candida albicans and C. glabrata ${ }^{60}$. Thus, our findings are pioneering this field. We found, for example, that similarly to bacterial microbiota, both Trichuris and Strongyloides helminths were positively associated with fungal richness in both yellow baboons and Udzungwa red colobus living in FF. However, since no data are available for comparison with our results, and the mechanism behind these associations is difficult to disentangle, we can only conclude that fungal richness, similarly to that of bacteria, is probably highly relevant for gut function ${ }^{61}$. However, the notion that either a competitive or a beneficial association between gut components exists cannot be verified at this time.

\section{Conclusions}

Although causal relationships must be further investigated, the current study underlines the importance of considering the associations between gut components in investigations of wild animal health and conservation status, especially in endangered species threatened by increasing human pressure. Our findings revealed that environmental factors may play an important role in shaping such associations. Thus, to clarify to what extent biological and environmental variables are interconnected, their transmission potential and the direct consequences on animal status, future studies would benefit from better classification of each gut component and determination of their metabolic functions, as well as broadening the investigations to include additional host gut components (e.g. viruses), and the microbiota of their surrounding ecosystem (e.g. sympatric hosts, food web, soil, water sources).

\section{Methods}

Study site and animal populations. We sampled faecal pellets of the Udzungwa red colobus (Procolobus gordonorum) and yellow baboon (Papio cynocephalus) following ${ }^{32}$ in the Udzungwa Mountains of Tanzania $\left(7^{\circ} 40^{\prime} \mathrm{S}\right.$ to $8^{\circ} 40^{\prime} \mathrm{S}$ and $35^{\circ} 10^{\prime} \mathrm{E}$ to $36^{\circ} 50^{\prime} \mathrm{E}$; Fig. 3), an internationally-recognized biodiversity hotspot ${ }^{62}$ extending over $19,000 \mathrm{~km}^{263}$. The Udzungwa Mountains are characterized by several disjunct forest blocks with different levels of protection (from national park to poorer protection in other types of reserve), which affect the conservation status of the primate populations living within them ${ }^{64,65}$. Remaining forests are threatened by intensive agriculture ${ }^{66}$, and primates outside the Udzungwa Mountains National Park (established in 1992 with an area of $150 \mathrm{~km}^{2}$ and elevational range from 351 to $2263 \mathrm{~m}$ a.s.l.) are particularly vulnerable to hunting and other human disturbance ${ }^{67}$.

Our two focal primate species differ in ecological niche and dietary strategy: the Udzungwa red colobus is arboreal and feeds mainly on leaves and stems, while the yellow baboon is terrestrial and omnivorous, foraging for arthropods, seeds, fruit and leaves, opportunistically raiding crops. The red colobus is endemic and IUCNVulnerable, while the yellow baboon is categorized as 'Least Concern'68. Both these species live in PF and FF. $\mathrm{PF}$ is an intact semi-deciduous to sub-montane and montane evergreen forest that lies in the eastern part of the Udzungwa Mountains National Park, while FF is flat, groundwater forest surrounded by villages and sugarcane plantations, approximately $6 \mathrm{~km}$ east of PF (area extension: $12 \mathrm{~km}^{2}$, altitude: 269 to $302 \mathrm{~m}$ a.s.l.; Figs. S1 and S2).

Sample collection, parasitological assessment and gut microbiota detection. To assess the diversity of and interactions between the helminth, fungal and bacterial components of the gut flora of the red colobus and yellow baboon, in June and July 2016 we followed social groups unobtrusively and collected freshly deposited faecal samples from the ground for 89 red colobus (belonging to 12 social groups, six in PF and six in FF) and 69 yellow baboons (five social groups, 3 from PF, 2 from FF; Fig. 3c) following ${ }^{32,33}$ methods.

Each faecal sample was divided in two parts: the subsamples used to identify helminths were preserved in $10 \mathrm{ml}$ of $10 \%$ neutral buffered formalin and stored at ambient temperature $\left(20-25^{\circ} \mathrm{C}\right)$ until transport to the Fondazione Edmund Mach (FEM), Italy where they were stored at $4{ }^{\circ} \mathrm{C}$ before shipment to the University of Veterinary Sciences in Brno, Czech Republic, for parasitological analysis. Helminth identification was carried 


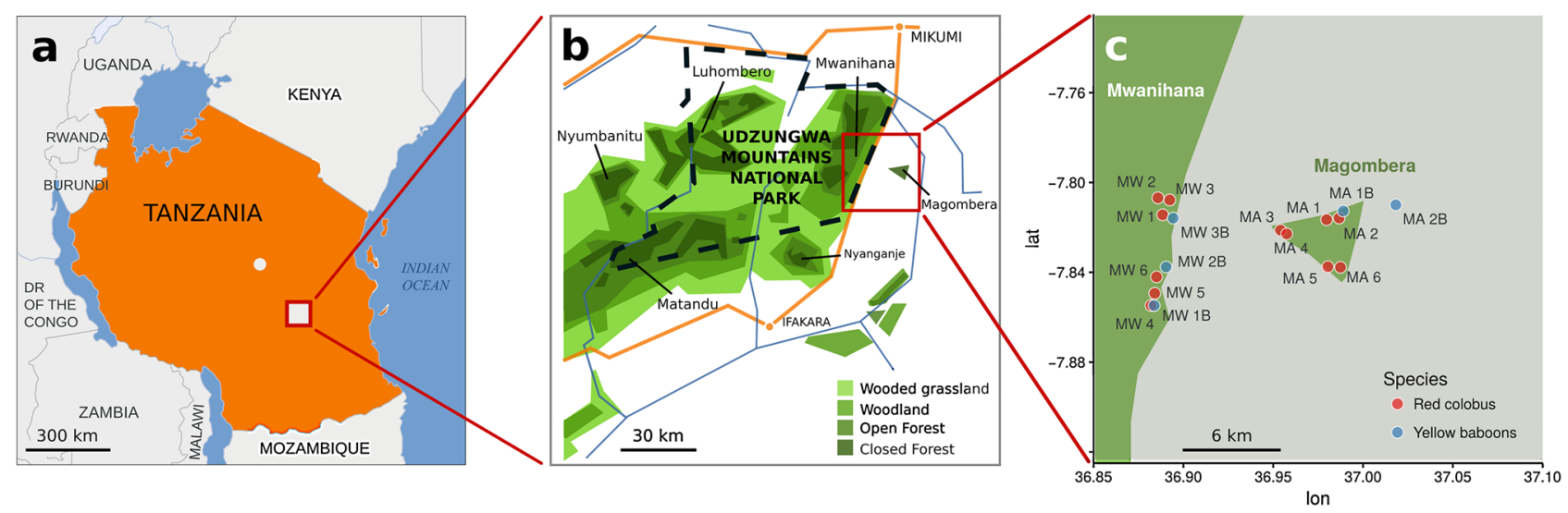

Figure 3. Map of the study site in the Udzungwa Mountains, Tanzania (a). Enlargement indicating the forested areas considered in this study: Mwanihana (protected forest) and Magombera (fragmented forest block) (b). Sample sites for Udzungwa red colobus (red circles: 12 social groups) and yellow baboons (blue circles: five social groups) (c). Dashed line in (b) indicates the border of the Udzungwa Mountains National Park. Original map reproduced with permission from ${ }^{32}$.

out using both modified Sheather's flotation and faecal sedimentation techniques ${ }^{69,70}$. In brief, from the whole sediment sample (see details $\mathrm{in}^{35}$ ) we examined $2 \mathrm{ml}$ of faecal suspension using optical microscopy at $400 \times$ magnification (OLYMPUS CX40, Japan). Based on morphological characteristics, eggs were identified for each helminth taxon. Lastly, using what was left of the faecal sample, adult and larval helminths were collected using the 'gauze-washing' method ${ }^{71}$ and observed via stereo microscopy (OLYMPUS SZ51, Japan) at 8-40× magnification.

The faecal subsamples used for microbiota analysis were preserved in $96 \%$ ethanol and kept at $4{ }^{\circ} \mathrm{C}$ before transporting them to FEM, stored at $-80^{\circ} \mathrm{C}$ and shipped to the University of Illinois, USA for analysis (described $i^{32}$ ). Briefly, from each faecal sample, we extracted and amplified the whole DNA using the same protocols ${ }^{72,73}$, and later sequenced the V1-V3 regions of the $16 \mathrm{~S}$ ribosomal RNA gene for bacteria and the ITS1-ITS2 region for fungi using Illumina MiSeq technology. The software MICCA ${ }^{74}$ was used to identify amplicon sequence variants (SVs).

Statistical analyses. All statistical analyses were conducted using the $R$ 4.0.2 statistical package ${ }^{75}$. Alpha and beta diversity indices of the bacterial and fungal components of the microbiota were calculated using the package phyloseq 1.32.0. Standard alpha diversity index (Chaol estimator of species richness and Shannon entropy) for both bacteria and fungi were estimated and used them as dependent variables in regression models testing the relationship between gut microbiota (bacterial and fungal) richness and helminth presence separately for each primate species in each forest type (PF and FF). To identify statistically significant effects of infection by helminths on bacterial and fungal richness we performed a post-hoc analysis on marginal means estimated using a Generalized Linear Model (GLM) that guarantees robust results for unbalanced study groups. Specifically, species richness (Chaol) and diversity (Shannon) of bacteria and fungi were used as dependent variables in a GLM with Poisson error distribution, with helminth presence ('Positive') or absence ('Negative') for dicrocoeliid trematodes, spirurid and strongylid nematodes, Strongyloides, and Trichuris as independent variables. The model used was:

$$
(\text { Chao1/Shannon } \sim \text { Species }+ \text { Parasite }+ \text { Forest }+ \text { Infected } \% \text { in } \%(\text { Species }+ \text { Parasite }+ \text { Forest })
$$

where Species indicates the primate species, Parasite indicates the helminth type, and Forest indicates PF or $\mathrm{FF}$, and Chaol/Shannon indicate either Chaol or Shannon entropy. Contrasts between marginal means for 'Positive' and 'Negative' groups for each primate species, parasite and forest and significant test were computed using the package emmeans 1.5 .3 on the fitted model ${ }^{76}$. The effect of helminth presence on beta diversity of bacteria and fungi was assessed by PERMANOVA using the function adonis2 from the vegan 2.5-7 package. Homogeneity of dispersions was controlled by ANOVA of the multivariate dispersions of the groups obtained using the function betadisper from the vegan 2.5-7 package. DESeq2 was used to identify which bacterial and fungal taxa explained the differences observed in their overall relative abundance between helminth infected and non-infected individuals.

Ethics statement. The authors confirm they did not interact with or disrupt any of the primate species surveyed in any way. Faecal sample collection was non-invasive, without direct contact or interaction with the animals. Highly trained fieldworkers strictly adhered to the 'Code of Best Practices for Field Primatology' published by the International Primatological Society (IPS) as well as the 'Principles for the Ethical Treatment of Primates' of the American Society of Primatologists (ASP). Data collection complied with legal requirements and laws governing wildlife research in Tanzania. Research permits (2016-267-ER-2009-49) were obtained through the Tanzania Commission for Science and Technology (COSTECH), Tanzania Wildlife Research Institute (TAWIRI) and Tanzania National Parks (TANAPA). 


\section{Data availability}

DNA sequences have been deposited in the European Nucleotide Archive (ENA) under study accession number PRJEB37770. 16S and ITS raw sequences generated for this study and metadata are publicly available at https:// doi.org/10.5281/zenodo.5482908. Scripts for statistics are available at https://github.com/compmetagen/barel li_et_al_scirep_2021.

Received: 10 May 2021; Accepted: 18 October 2021

Published online: 03 November 2021

\section{References}

1. Zaiss, M. M. \& Harris, N. L. Interactions between the intestinal microbiome and helminth parasites. Parasite Immunol. 38, 5-11 (2016).

2. Cortés, A., Peachey, L. E., Jenkins, T. P., Scotti, R. \& Cantacessi, C. Helminths and microbes within the vertebrate gut-not all studies are created equal. Parasitology 146, 1371-1378 (2019).

3. Sender, R., Fuchs, S. \& Milo, R. Revised estimates for the number of human and bacteria cells in the body. PLoS Biol. 14, e1002533 (2016).

4. Claesson, M. J. et al. Gut microbiota composition correlates with diet and health in the elderly. Nature 488, 178-184 (2012).

5. Clemente, J. C., Ursell, L. K., Parfrey, L. W. \& Knight, R. The impact of the gut microbiota on human health: An integrative view. Cell 148, 1258-1270 (2012).

6. McFall-Ngai, M. et al. Animals in a bacterial world, a new imperative for the life sciences. Proc. Nat. Acad. Sci. 110, 3229-3236 (2013).

7. Hooper, L. V., Littman, D. R. \& Macpherson, A. J. Interactions between the microbiota and the immune system. Science 336, 1268-1273 (2012)

8. Tremaroli, V. \& Bäckhed, F. Functional interactions between the gut microbiota and host metabolism. Nature 489, 242-249 (2012).

9. Brown, E. M., Sadarangani, M. \& Finlay, B. B. The role of the immune system in governing host-microbe interactions in the intestine. Nat. Immunol. 14, 660-667 (2013).

10. Kim, S., Covington, A. \& Pamer, E. G. The intestinal microbiota: Antibiotics, colonization resistance, and enteric pathogens. Immunol. Rev. 279, 90-105 (2017).

11. Ducarmon, Q. R. et al. Gut microbiota and colonization resistance against bacterial enteric infection. Microbiol. Mol. Biol. Rev. 83, e00007-19 (2019).

12. Sorbara, M. T. \& Pamer, E. G. Interbacterial mechanisms of colonization resistance and the strategies pathogens use to overcome them. Mucosal Immunol. 12, 1-9 (2019).

13. Jourdan, P. M., Lamberton, P. H. L., Fenwick, A. \& Addiss, D. G. Soil-transmitted helminth infections. Lancet 391, 252-265 (2018).

14. Wammes, L. J., Mpairwe, H., Elliott, A. M. \& Yazdanbakhsh, M. Helminth therapy or elimination: Epidemiological, immunological, and clinical considerations. Lancet Infect. Dis. 14, 1150-1162 (2014).

15. Jenkins, T. P. et al. Experimental infection with the hookworm, Necator americanus, is associated with stable gut microbial diversity in human volunteers with relapsing multiple sclerosis. BMC Biol. 19, 1-17 (2021).

16. Holm, J. B. et al. Chronic Trichuris muris infection decreases diversity of the intestinal microbiota and concomitantly increases the abundance of Lactobacilli. PLoS ONE 10, e0125495 (2015).

17. Ducarmon, Q. R. et al. Dynamics of the bacterial gut microbiota during controlled human infection with Necator americanus larvae. Gut Microbes 12, 1840764 (2020).

18. Broadhurst, M. J. et al. Therapeutic helminth infection of macaques with idiopathic chronic diarrhea alters the inflammatory signature and mucosal microbiota of the colon. PLoS Pathog. 8, e1003000 (2012).

19. Kreisinger, J., Bastien, G., Hauffe, H. C., Marchesi, J. \& Perkins, S. E. Interactions between multiple helminths and the gut microbiota in wild rodents. Philos. Trans. R. Soc. Lond. B Biol. Sci. 370, 20140295 (2015).

20. Filyk, H. A. \& Osborne, L. C. The multibiome: The intestinal ecosystem's influence on immune homeostasis, health, and disease. EBioMedicine 13, 46-54 (2016).

21. Cantacessi, C. et al. Impact of experimental hookworm infection on the human gut microbiota. J. Infect. Dis. 210, 1431-1434 (2014).

22. Li, R. W. et al. Alterations in the porcine colon microbiota induced by the gastrointestinal nematode Trichuris suis. Infect. Immun. 80, 2150-2157 (2012).

23. Reynolds, L. A., Brett Finlay, B. \& Maizels, R. M. Cohabitation in the intestine: Interactions among helminth parasites, bacterial microbiota, and host immunity. J. Immunol. 195, 4059-4066 (2015).

24. Lee, S. C. et al. Helminth colonization is associated with increased diversity of the gut microbiota. PLoS Negl. Trop. Dis. 8, e2880 (2014).

25. Rosa, B. A. et al. Differential human gut microbiome assemblages during soil-transmitted helminth infections in Indonesia and Liberia. Microbiome 6, 33 (2018).

26. Newbold, L. K. et al. Helminth burden and ecological factors associated with alterations in wild host gastrointestinal microbiota. ISME J. 11, 663-675 (2017).

27. Baxter, N. T. et al. Intra- and interindividual variations mask interspecies variation in the microbiota of sympatric Peromyscus populations. Appl. Environ. Microbiol. 81, 396-404 (2015).

28. Cooper, P. et al. Patent human infections with the whipworm, Trichuris trichiura, are not associated with alterations in the faecal microbiota. PLOS ONE 8, e76573 (2013).

29. Rapin, A. \& Harris, N. L. Helminth-bacterial interactions: Cause and consequence. Trends Immunol. 39, 724-733 (2018).

30. Cowlishaw, G. \& Dunbar, R. I. Primate Conservation Biology (University of Chicago Press, 2000).

31. Estrada, A. et al. Impending extinction crisis of the world's primates: Why primates matter. Sci. Adv. 3, e1600946 (2017).

32. Barelli, C. et al. The gut microbiota communities of wild arboreal and ground-feeding tropical primates are affected differently by habitat disturbance. mSystems 5, 3 (2020).

33. Barelli, C. et al. Habitat fragmentation is associated to gut microbiota diversity of an endangered primate: Implications for conservation. Sci. Rep. 5, 14862 (2015).

34. Barelli, C. et al. Altitude and human disturbance are associated with helminth diversity in an endangered primate, Procolobus gordonorum. PLoS ONE 14, e0225142 (2019).

35. Barelli, C. et al. Loss of protozoan and metazoan intestinal symbiont biodiversity in wild primates living in unprotected forests. Sci. Rep. 10, 1-12 (2020).

36. Aivelo, T. \& Norberg, A. Parasite-microbiota interactions potentially affect intestinal communities in wild mammals. J. Anim. Ecol. 87, 438-447 (2018).

37. Vlčková, K. et al. Relationships between gastrointestinal parasite infections and the fecal microbiome in free-ranging western lowland gorillas. Front. Microbiol. 9, 1202 (2018). 
38. Mann, A. E. et al. Biodiversity of protists and nematodes in the wild nonhuman primate gut. ISME J. 14, 609-622 (2020).

39. de Winter, I. I. et al. Effects of seasonality and previous logging on faecal helminth-microbiota associations in wild lemurs. Sci. Rep. 10, 16818 (2020).

40. Ghai, R. R. et al. Hidden population structure and cross-species transmission of whipworms (Trichuris sp.) in humans and nonhuman primates in Uganda. PLoS Negl. Trop. Dis. 8, e3256 (2014).

41. Nutman, T. B. Human infection with Strongyloides stercoralis and other related Strongyloides species. Parasitology 144, 263-273 (2017).

42. Stephenson, L. S., Holland, C. V. \& Cooper, E. S. The public health significance of Trichuris trichiura. Parasitology 121, S73-S95 (2000).

43. Viney, M. E. The biology of Strongyloides spp. WormBook https://doi.org/10.1895/wormbook.1.141.2 (2015).

44. Renelies-Hamilton, J. et al. Exploring interactions between Blastocystis sp., Strongyloides spp. and the gut microbiomes of wild chimpanzees in Senegal. Infect. Genet. Evol. 74, 104010 (2019).

45. Afrin, T. et al. Sequential changes in the host gut microbiota during infection with the intestinal parasitic nematode. Front. Cell Infect. Microbiol. 9, 217 (2019).

46. Rubel, M. A. et al. Lifestyle and the presence of helminths is associated with gut microbiome composition in Cameroonians. Genome Biol. 21, 122 (2020).

47. Jenkins, T. P. et al. Author Correction: A comprehensive analysis of the faecal microbiome and metabolome of Strongyloides stercoralis infected volunteers from a non-endemic area. Sci. Rep. 9, 8571 (2019).

48. Lozupone, C. A., Stombaugh, J. I., Gordon, J. I., Jansson, J. K. \& Knight, R. Diversity, stability and resilience of the human gut microbiota. Nature 489, 220-230 (2012).

49. van der Zande, H. J. P., Zawistowska-Deniziak, A. \& Guigas, B. Immune regulation of metabolic homeostasis by helminths and their molecules. Trends Parasitol. 35, 795-808 (2019).

50. Maeda, Y. \& Takeda, K. Host-microbiota interactions in rheumatoid arthritis. Exp. Mol. Med. 51, 1-6 (2019).

51. Biddle, A., Stewart, L., Blanchard, J. \& Leschine, S. Untangling the genetic basis of fibrolytic specialization by Lachnospiraceae and Ruminococcaceae in diverse gut communities. Diversity 5, 627-640 (2013).

52. Brulc, J. M. et al. Gene-centric metagenomics of the fiber-adherent bovine rumen microbiome reveals forage specific glycoside hydrolases. Proc. Natl. Acad. Sci. USA 106, 1948-1953 (2009).

53. Hale, V. L. et al. Diet versus phylogeny: A comparison of gut microbiota in captive Colobine monkey species. Microb. Ecol. 75, 515-527 (2018).

54. Trosvik, P. et al. Multilevel social structure and diet shape the gut microbiota of the gelada monkey, the only grazing primate. Microbiome 6, 84 (2018)

55. Liu, B. et al. Western diet feeding influences gut microbiota profiles in apoE knockout mice. Lipids Health Dis. 17, 159 (2018).

56. Bhute, S. S. et al. Gut microbial diversity assessment of Indian Type-2-diabetics reveals alterations in Eubacteria, Archaea, and Eukaryotes. Front. Microbiol. 8, 214 (2017).

57. Wang, Y. et al. Phocea, Pseudoflavonifractor and Lactobacillus intestinalis: Three potential biomarkers of gut microbiota that affect progression and complications of obesity-induced Type 2 diabetes Mellitus. Diabetes Metab. Syndr. Obes. 13, 835-850 (2020).

58. Yarahmadi, M. et al. The anti-giardial effectiveness of fungal and commercial chitosan against Giardia intestinalis cysts in vitro. J. Parasit. Dis. 40, 75-80 (2016).

59. Dinleyici, E. C. et al. Clinical efficacy of Saccharomyces boulardii or metronidazole in symptomatic children with Blastocystis hominis infection. Parasitol. Res. 108, 541-545 (2011).

60. Lepczyńska, M. \& Dzika, E. The influence of probiotic bacteria and human gut microorganisms causing opportunistic infections on ST3. Gut Pathog. 11, 6 (2019).

61. Huseyin, C. E., O’Toole, P. W., Cotter, P. D. \& Scanlan, P. D. Forgotten fungi-the gut mycobiome in human health and disease. FEMS Microbiol. Rev. 41, 479-511 (2017).

62. Mittermeier, R. A., Myers, N., Gill, P. C. \& Mittermeier, C. G. Hotspots: Earth's Richest and Most Endangered Terrestrial Ecoregions (CEMEX, 2000).

63. Platts, P. J. et al. Delimiting tropical mountain ecoregions for conservation. Environ. Conserv. 38, 312-324 (2011).

64. Ruiz-Lopez, M. J. et al. A novel landscape genetic approach demonstrates the effects of human disturbance on the Udzungwa red colobus monkey (Procolobus gordonorum). Heredity 116, 167-176 (2016).

65. Cavada, N., Tenan, S., Barelli, C. \& Rovero, F. Effects of anthropogenic disturbance on primate density at the landscape scale. Conserv. Biol. 33, 873-882 (2019).

66. Laurance, W. F. et al. Averting biodiversity collapse in tropical forest protected areas. Nature 489, 290-294 (2012).

67. Rovero, F. et al. Primates decline rapidly in unprotected forests: Evidence from a monitoring program with data constraints. PLoS ONE 10, e0118330 (2015).

68. International Union for the Conservation of Nature and Natural Resources (IUCN). 2021. IUCN red list of threatened species version 2020-2. International Union for the Conservation of Nature and Natural Resources http://www.iucnredlist.org. (Accessed 21 Apr 2021).

69. Modrý, D., Pafčo, B., Petrželková, K. J. \& Hasegawa, H. Parasites of Apes: An Atlas of Coproscopic Diagnostics (2018).

70. Gillespie, T. R. Noninvasive assessment of gastrointestinal parasite infections in free-ranging primates. Int. J. Primatol. 27, 1129$1143(2006)$.

71. Hasegawa, H. Methods of collection and identification of minute nematodes from the feces of primates, with special application to coevolutionary study of pinworms. In Primate Parasite Ecology: The Dynamics of Host-parasite Relationships (eds Huffman, M. A. \& Chapman, C. A.) 29-46 (Cambridge University Press, 2009).

72. Mallott, E. K., Malhi, R. S. \& Garber, P. A. High-throughput sequencing of fecal DNA to identify insects consumed by wild Weddell's saddleback tamarins (Saguinus weddelli, Cebidae, Primates) in Bolivia. Am. J. Phys. Anthropol. 156, 474-481 (2015).

73. Mallott, E. K., Garber, P. A. \& Malhi, R. S. Integrating feeding behavior, ecological data, and DNA barcoding to identify developmental differences in invertebrate foraging strategies in wild white-faced capuchins (Cebus capucinus). Am. J. Phys. Anthropol. 162, 241-254 (2017).

74. Albanese, D., Fontana, P., De Filippo, C., Cavalieri, D. \& Donati, C. MICCA: A complete and accurate software for taxonomic profiling of metagenomic data. Sci. Rep. 5, 9743 (2015).

75. R Core Team. R: A Language and Environment for Statistical Computing (R Foundation for Statistical Computing, 2021) https:// www.R-project.org.

76. Lenth, R., Singmann, H., Love, J., Buerkner, P. \& Herve, M. Emmeans: Estimated marginal means, aka least-squares means. R package version, Vol. 1, 3 (2018) https://CRAN.R-project.org/package=emmeans.

\section{Acknowledgements}

We are very grateful to the Tanzania Commission for Science and Technology (COSTECH), Tanzania Wildlife Research Institute (TAWIRI) and Tanzania National Parks (TANAPA) for granting us permissions to conduct the study (COSTECH Permit n. 2016-267-ER-2009-49). Data collection and analyses were funded by the European 
Union's Horizon 2020 research and innovation programme under the Marie Sklodowska-Curie grant agreement No 752399 (Project WILDGUT).

\section{Author contributions}

C.B. and H.C.H. conceived and designed the study and obtained the funding. C.B. and F.R. collected field data and samples. C.B., B.P. and D.M. performed and supervised the parasitological analyses. C.D. and D.A. conducted bioinformatic and statistical analyses. C.B. wrote the first draft of the manuscript. All other authors actively reviewed and contributed to the manuscript.

\section{Competing interests}

The authors declare no competing interests.

\section{Additional information}

Supplementary Information The online version contains supplementary material available at https://doi.org/ 10.1038/s41598-021-01145-1.

Correspondence and requests for materials should be addressed to C.B.

Reprints and permissions information is available at www.nature.com/reprints.

Publisher's note Springer Nature remains neutral with regard to jurisdictional claims in published maps and institutional affiliations.

(c) (i) Open Access This article is licensed under a Creative Commons Attribution 4.0 International License, which permits use, sharing, adaptation, distribution and reproduction in any medium or format, as long as you give appropriate credit to the original author(s) and the source, provide a link to the Creative Commons licence, and indicate if changes were made. The images or other third party material in this article are included in the article's Creative Commons licence, unless indicated otherwise in a credit line to the material. If material is not included in the article's Creative Commons licence and your intended use is not permitted by statutory regulation or exceeds the permitted use, you will need to obtain permission directly from the copyright holder. To view a copy of this licence, visit http://creativecommons.org/licenses/by/4.0/.

(C) The Author(s) 2021 